\title{
The Psychosocial Condition of Syrian Children Facing a Precarious Future
}

\author{
MAHA SHUAYB AND NADER AHMAD
}

\section{Abstract}

This study investigates the psychosocial conditions of Syrian refugees and vulnerable Lebanese children in Lebanese public schools. A survey was conducted with Syrian and Lebanese children and their parents. Interviews with public school staff were also carried out. The study found that poverty and war play equal roles in affecting children's emotional well-being as Syrian and Lebanese children manifest similar levels of anxiety and hyperactivity. While the past presents significant stressors, present and future stressors were also identified amongst refugees. This article critiques the prime emphasis of psychosocial intervention paradigms on past trauma, which risks overlooking present and future stressors. It argues that the psychosocial conditions of refugees are interpreted in isolation from refugees' poverty, subordinated social status, and the local injustices to which they are subject.

\section{Résumé}

Cette étude examine les conditions psychosociales des enfants réfugiés syriens et des enfants libanais vulnérables dans les écoles publiques libanaises. Un sondage a été réalisé auprès d'enfants syriens et libanais et de leurs parents. Des entrevues avec le personnel scolaire ont aussi été effectuées. Létude démontre que la pauvreté et la guerre affectent de manière égale le bien-être émotionnel des enfants, les enfants syriens et libanais manifestant des niveaux similaires d'anxiété et d'hyperactivité. Alors que le passé comporte des facteurs de stress significatifs, des facteurs de stress présents et futurs ont aussi été identifiés chez les réfugiés. Cet article critique les paradigmes d'intervention psychosociale qui mettent laccent sur les traumatismes passés, au risque de négliger les facteurs de stress présents et futurs. Larticle soutient que les conditions psychosociales des réfugiés sont interprétées indépendamment de leur pauvreté, de leur statut social subordonné et des injustices locales dont ils font l'objet.

\section{Introduction}

$\mathrm{L}$ ebanon maintains one of the highest ratios of refugees relative to its population in the world. According to the United Nations and the Lebanese government, one in three people in Lebanon is either a displaced Palestinian or Syrian refugee (Government of Lebanon \& UNHCR, 2019). Education has been a main area of humanitarian response, including considerable efforts to offer education specifically to Syrian refugees. In 2016, the United Nations High Com-

Cette œuvre en libre accès fait l'objet d'une licence Creative Commons Attribution-NonCommercial 4.0 International Licence, laquelle autorise l'utilisation, la reproduction et la distribution de l'œuvre sur tout support à des fins non commerciales, pourvu que l'auteur ou les auteurs originaux soient mentionnés et que la publication originale dans Refuge: revue canadienne sur les réfugiés soit citée. 
missioner for Refugees (UNHCR) estimated the number of Syrian children in Lebanon at 488,832 (MEHE, 2016). Despite efforts to offer education to Syrian refugees, enrolment rates in formal education do not exceed $40 \%$, with only $1 \%$ currently enrolled in grade 9 (MEHE, 2019). Following the Syrian crisis (which began on March 15, 2011), the demands on Lebanese public schools increased, resulting in the opening of two school shifts for all students: one in the morning ( 8 to 1 ) and another in the afternoon ( 2 to 6 ). However, enrolment in the afternoon shift is restricted to Syrian children, and they are offered a more concise version of the Lebanese curriculum. Currently, over $65 \%$ of Syrian refugee children enrolled in school attend the afternoon shift (MEHE, 2020).

The public education sector, which presented numerous weaknesses prior to the crisis, is now further affected by the influx of the significant number of school-aged refugee children, compared to school-aged Lebanese children. Public schools are ill-equipped and under-resourced to deal with this situation. Prior to the Syrian crisis, around $30 \%$ of school-enrolled children were attending the public education system. Low enrolment in primary public schools was in response to the poor quality of education offered. To respond to the Syrian crisis, the Ministry of Education and Higher Education (MEHE), with the support of UN agencies and donor communities, developed two consecutive threeyear education strategies (RACE I and RACE II) to absorb Syrian refugee children in public schools and strengthen the public school system. Still, many teachers are unable to cope with the challenges of larger classes, the two-shift school day, and pupils from extremely disadvantaged backgrounds (Shuayb et al., 2014).

This study was conducted in 2015, three years after the arrival of hundreds of thousands of Syrian refugees. The trauma from the war was very fresh in refugees' minds and hearts. As a result, addressing the psychological needs of refugee children has occupied a considerable part of relief responses following the Syrian refugee crisis. In this article, we are interested in understanding the psychological stressors facing Syrian children in Lebanon and examining how schools have responded to their needs.

School can be a form of psychosocial support for children in emergencies. School provides a safe space for children, stabilizes and normalizes everyday routines, and offers them a sense of control and belonging by being a predictable factor in contexts often dominated by loss and violence. At the same time, school may trigger more trauma and unhappiness as a result of bullying and discrimination, etc. The few existing studies on the psychosocial well-being of Syrian children in Lebanon report high levels of insecurity, isolation, and pervasive symptoms of distress, such as trouble with sleeping, horrifying flashbacks, bedwetting, or speech problems (UNHCR, 2013, 2015). Similarly, Abou-Saleh and Mobayad (2013) discovered a high prevalence of PTSD (41\%-76\%) among children in camps. The main predictor was the number of traumatic experiences children encountered related to the conflict. Positive coping mechanisms included going out, exercising, and playing with other children. Negative coping mechanisms included smoking, watching television, and being idle. A study by Pérez-Sales (2013) reveals that feelings of humiliation-linked to the frustration of having a high dependency on aid-are prevalent among Syrian refugees.

Susceptibility to stress in adolescents with higher levels of economic pressure is well captured in the conservation of resources theory (Khamis, 2012; Hobfoll, 1989). According to this theory, loss of resources is the primary mechanism through which stressful life events affect adolescents' psychological health.

This study investigates the psychosocial conditions and lived stressors of Syrian refugee and Lebanese children in public schools in Lebanon. The article is divided into three main sections. In the first section, we situate our research by examining the research on the psychosocial needs of Syrian refugees and the main paradigms of intervention. This is followed by research methodology and data analysis, respectively. The findings are presented under three main themes: psychosocial well-being and school experience; psychosocial support provisions; and sources of psychosocial distress.

\section{Psychosocial Intervention Paradigms in a Refugee Context: Current Debates}

To situate our study of the psychological needs of and interventions for refugee children in Lebanon, we will examine the main paradigms and schools of thought that shape the field. Recent literature presents two primary paradigms to address the psychological strains prompted by refugee crises around the world: clinical and psychosocial. The clinical trauma-focused approach emphasizes war-related trau$\mathrm{ma}$ as the main source of distress. It advocates case-focused support targeting individuals. Its objective is to support the mental health and psychosocial well-being of individuals by providing emotional support or clinical mental health services, in an attempt to help them cope with their distress using their own strengths and social networks (Hassan et al., 2016). There are several limitations in the clinical approach, including that the narrow focus of post-traumatic stress disorder (PTSD) and traumatic experiences undermines the post-displacement stressors of everyday life, which are major sources of mental and social problems (Berthold, 2000; Betancourt et al., 2013; Alfadhli \& Drury, 2016). Refugees in local communities, are predominantly affected by overcrowded housing, 
poverty, unemployment, insecurity, exploitation, and poor health (Panter-Brick et al., 2008). These challenges may converge with symptoms of PTSD or clinical depression (Patel, 2014; Hassan et al., 2016).

In contrast, the psychosocial support paradigm emphasizes current experiences in refugee destination countries as the main sources of distress. While there is no universally accepted definition of psychosocial interventions in the literature, it is commonly agreed that they comprise interpersonal or informational activities, techniques, or strategies that target biological, behavioural, cognitive, emotional, interpersonal, social, or environmental factors to improve health and well-being (Institute of Medicine, 2015). This approach promotes ad hoc localized interventions to alleviate the challenges of daily life, such as shelter, food, and monetary assistance as well as specialized clinical services for specific cases (IASC, 2007). In this paradigm, psychosocial support includes raising awareness about diversity and discrimination in order to reduce tension between local communities and newcomers through capacity-building programs and cultural events (Atlas, 2009). Psychosocial interventions have been found to have beneficial effects on PTSD, depression, and anxiety symptoms (Turrini et al., 2019; Nosè et al., 2017). Yet there is little evidence on the impact of psychosocial interventions on refugee children (Turrini et al., 2019; Fazel, 2018). Critics argue that these interventions risk subordinating refugees and creating dependency on the resources and expertise of practitioners (Gupte \& Mehta, 2009; Alfadhli \& Drury, 2016). This uneven power dynamic places newcomers in a state of powerlessness, which often erodes their individual agency (Hassan et al., 2016).

To conclude, refugees are often faced with two options: either live in a condition of powerlessness and dependence on paltry services and assistance, or put one's life at a higher risk in the quest to live with dignity, in justice, and with self-determination. All too often, confinement, social isolation, or putting oneself at risk are the price of mere existence. Displaced children share much of this fate with their parents (Huyck \& Fields, 1981). They suffer the repercussions of a form of double exclusion. The first is experienced in the form of family neglect, violence, and disintegration as a result of the heavy weight of repression and exclusion experienced by their parents. The second is experienced in education (Shuayb, 2014; Bush \& Saltarelli, 2000).

\section{Methodology}

The research methodology comprises five case studies of upper primary public schools offering two shifts: a morning one for Syrian and Lebanese and an afternoon one for Syrian children only. The research instruments included a quantitative survey, individual interviews with school principals, teachers, and counsellors, as well as focus groups with children and parents.

\section{Quantitative Surveys}

A quantitative survey was administered to students, their parents, and teachers in each public school. The questionnaires investigating the emotional well-being of children (filled out by children as well as their parents) were based on Goodman's One-Sided Strengths and Difficulties Questionnaire. ${ }^{1}$ The quantitative data of the students' survey examined six variables, each comprising three to five items. Designed to measure students' psychosocial condition, these quantitative variables examine students' (1) emotions, (2) conduct, (3) hyperactivity, (4) relation to family, (5) relation to peers, and (6) relation to school.

\section{Qualitative Interviews and Focus Groups}

We conducted one-to-one interviews with principals, teachers, counsellors, supervisors (enrolled both in the morning and afternoon shifts), children who dropped out of school, and their parents. Focus group interviews were conducted with Syrian children and parents of Syrian and Lebanese children to explore the stressors children are exposed to and their coping mechanisms.

\section{Sample}

A convenience sampling was followed in this study in response to the restrictions imposed by the MEHE, including reserving the selection of schools for any research study for the Project Management Unit (PMU) which was developed specifically to manage the education response for Syrian refugees. As a result, this study's sample was not representative of the refugee population. However, to tackle this drawback, we sent criteria to the PMU at the MEHE that aimed to cover the main characteristics of schools, and the geographical locations where the majority of refugees resided. These criteria helped decrease the bias of a convenience sampling. The criteria sent to PMU included selecting public schools that included a large number of Syrian refugees in both urban and rural locations. We also specified that the schools must have two shifts (morning and afternoon). The last criterion included the geographical locations with the largest concentration of refugees (Akkar, the Bekaa, and Beirut). A letter was sent to MEHE requesting permission to conduct the study and specifying the criteria of the five public schools. MEHE then nominated five schools for the study on the basis of our

1. Available from https://www.sdqinfo.org/ao.html 
Table 1. Study Sample

\begin{tabular}{lcc}
\hline Type of participants & Number quantitatively surveyed & Number interviewed \\
\hline Students & 248 & 49 \\
Principals and school supervisors & 9 & 10 \\
Teachers & 18 & 8 \\
Parents & 18 & 32 \\
Counsellors & 1 & 2 \\
\hline
\end{tabular}

Table 2. Number of Surveyed Syrian and Lebanese Students in Morning and Afternoon Shifts

\begin{tabular}{lcccc}
\hline School regions & Lebanese morning & Syrian morning & Total morning & $\begin{array}{c}\text { Total afternoon } \\
\text { (all Syrian) }\end{array}$ \\
\hline Mount Lebanon & 132 & 65 & 197 & 600 \\
Akkar & 217 & 258 & 475 & 590 \\
The Bekaa & 137 & 85 & 222 & 466 \\
\hline
\end{tabular}

criteria. The five schools selected for the case study represent different regions in Lebanon (urban, rural, north, south, and centre). The schools were located in a deprived area of Beirut, Akkar, and the Bekaa where the local Lebanese population suffers from extreme poverty. It is worth noting that the majority of Syrian refugees reside in the poorest areas in Lebanon because the rent is cheaper and living expenses are lower (LCRP, 2015). Table 1 presents an overview of the sample.

The survey sample covers students in grades 4 and 7 during both morning and afternoon shifts (ages 10-15). In the student sample, $42 \%$ were Lebanese and $60 \%$ were female. We randomly selected an equal number of girls and boys from the same grades to participate in the focus groups. Only individual schools could contact the parents to invite them to participate in the focus groups. The majority of parents who participated in the focus groups were female, probably because fathers were working, and in a patriarchal society, mothers deal with school matters. All but three interviewed teachers were female. Most of the children had fled Syria to Lebanon two years earlier, in 2012. Those who took refuge in the Bekaa and Akkar fled from rural Syria.

Many of the morning classes had fewer than 15 students, while afternoon classes had 30 or more. In contrast, all classrooms in afternoon schools we visited had 30 to 36 students. Syrian children who attended the morning shift had often been enrolled in the school for at least two years. However, it is worth noting that quite a few of children in the afternoon shift had been enrolled previously but were not allowed to register in the morning shift, although there was capacity in at least two of the visited schools. The main reason for their rejection was that half the children in the morning shift must be Lebanese.

The majority of the surveyed Syrian refugee children had missed at least one year of schooling. Just under half of the surveyed Syrian refugee children (44\%) missed one to two years, one-third missed three to four years, while $2 \%$ missed five years of schooling. Class repetition was common among both Syrian and Lebanese children. One-third of the surveyed Syrian children compared to $38 \%$ of Lebanese students repeated one to two years of their schooling. Just under half (45\%) of those who had repeated one to two years of schooling attended the morning shift, while only onethird were in the afternoon shift. Although students were struggling academically, both Syrian and Lebanese parents reported limited ability to support their children, particularly in subjects taught in foreign languages.

\section{Data Analysis}

Descriptive statistical data were generated to analyze quantitative data gathered from the Strengths and Difficulties Questionnaire using Statistical Product and Service Solutions. These included percentages, mean, and cross tabulation. In addition, variables were computed to create scales. In order 
to assess whether there were significant differences between the emotional well-being of Syrian and Lebanese children, we conducted chi-squared tests. Qualitative data, which included focus group interviews with parents and students as well as individual interviews with teachers, principals, and school counsellors, were transcribed (and translated where appropriate) and were analyzed using qualitative coding software (NVivo). Our analytical framework was based on a combination of emic codes derived from the content of the interviews and etic codes that reflected important themes identified through our literature on refugee education policies. The main themes were psychosocial conditions of refugees, support provisions, and types of stressors. Sub-codes for each main code emerged from reading and analyzing the interviews.

\section{Limitations}

As mentioned earlier, convenience sampling was used for this study because the MEHE restricted the selection of the schools. To address the bias associated with a convenience sample, we sent criteria to MEHE for consideration when selecting the schools for our study. Since we were interested in the differences between Syrian and Lebanese students, we collected data from schools that operated morning and afternoon shifts. To reduce sampling bias, we collected data from all three main governorates with the largest concentrations of Syrian refugees. We also sought to equally cover urban and rural areas as well as both sexes. However, convenience sampling does not allow us to make generalizations about our target populations. As a result, the quantitative results reported here indicate phenomena of interest and, in conjunction with our rich qualitative data, offer insights into the psychosocial well-being and school experiences of Syrian and Lebanese students in Lebanese public schools.

\section{Findings}

The findings of the study were grouped under three main headings: children's psychosocial well-being, sources of distress, and current interventions.

\section{Psychosocial Well-being and School Experience}

The statistical analysis shows that the overall emotional well-being of both Syrian and Lebanese students is in the range of normal, ${ }^{2}$ including basic emotions, conduct, and degree of hyperactivity, as well as relations to peers, school, and family. However, when isolating each variable, students' conduct, hyperactivity, and peer relations appear to be in the borderline range and close to abnormal. Despite the normal- ity of the overall results, the statistical analysis shows that the difference is significant when comparing Syrian children's overall well-being to that of Lebanese children. A closer look reveals that Lebanese children are more likely to report higher levels of misconduct at the $5 \%$ significance level $(p<0.05)$, hyperactivity at the $1 \%$ significance level $(p<0.01)$, and weak relations to school at the $5 \%$ significance level $(p<0.05)$. However, no significant difference was recorded at the level of emotion and relation to family.

A closer look at the quantitative figures recorded no significant difference between Syrian and Lebanese children in regard to feeling perpetually anxious and nervous, having constant fears, or often feeling unhappy. However, Lebanese were $5 \%$ more likely to report perpetual feelings of anger and engage in scuffles, compared to Syrian children. They were also $5 \%$ more likely to feel restless compared to their Syrian peers. Syrian children were $1 \%$ more likely to report liking school compared to Lebanese children, and 5\% more likely to finish what they started. However, Syrian parents in the focus group discussions, particularly of children in the afternoon shift, stated that their children felt afraid when going to or from school as a result of the violence and bullying they experienced. Their view was supported by quantitative data from the survey of Syrian children who reported higher percentages of feeling afraid, compared to Lebanese children, although this was not statistically significant.

Bullying and physical violence were relatively common among both Syrian and Lebanese students during both shifts. There were few differences between the responses of Syrian and Lebanese students in the quantitative data, which were not statistically significant. However, school staff reported that a significant number of Syrian children bullied and physically abused each other. Both teachers and administrators reported that Syrian children were fidgety and restless, and they constantly distracted their peers, interrupted their teachers, and had difficulty concentrating. Furthermore, teachers pointed out that some Lebanese children ridiculed the Syrian accent, which exacerbated tensions.

Physical and verbal violence was prevalent among Syrian and Lebanese students in both shifts. In all schools that we visited, principals reported verbal and physical violence between students in the morning and afternoon shifts. In one school, children who were part of a focus group reported knifings and sexual harassment. The main strategy employed by all principals to address violence was to separate students by having them follow different routes when morning children left and afternoon children arrived. In

2. Based on the original three-band categorizations of Goodman's Strengths \& Difficulties Questionnaire for 4- to 17-year-olds (Goodman et al. 1998). 
addition to this strategy, one principal threatened to take students to the police station if they ever fought. Parents of Syrian children also reported that a primary challenge to their children was lack of safety at or on the way to and from school.

School had different meanings for Syrian children. On the one hand, there was discrimination, bullying, and danger on the way to and from school. On the other hand, school presented freedom from the difficult situation that they experienced at home and uncertainties about their future. In addition, dire housing and living conditions plagued by insecurity could be one reasons that school appeared to be more satisfying for Syrian children than for their Lebanese peers. It is worth noting that the majority of interviewed parents and children reported that, on average, a family of six individuals lived in one room. Some parents prohibited their children, especially girls, from leaving the house out of fear for their security. As one parent noted, "It [the school] is the only place they can meet other children and run." Principals commented on the hyperactivity of Syrian children on the playground. One principal reported, "I have never seen this amount of running in the playground except by Syrian children." Students' expectations were reflected in the improvements they recommended for their school. When asked to name four main things they would like to change, a majority of Syrian and Lebanese students reported the need to improve school facilities, responsiveness of school staff, extracurricular activities, and protection from bullying and interruptive behaviour during class. Specifically they wished for better seats, heating, library, clubs, and sanitation, in addition to extracurricular activities such as arts and sports, and longer breaks in the afternoon shift.

These results confirm the work of other scholars, who found that poverty and a poor schooling experience can have major impacts on children's emotional well-being (Banerjee et al., 2016; McLoyd, 1998; Khamis, 2015; Hobfoll, 1989), as reported by Lebanese children in this study. They also had more negative views about their schooling experience than their Syrian peers. This could be partly the result of a higher sense of entitlement as citizens.

\section{Psychosocial Support}

As mentioned in the methodology, qualitative interviews were conducted with school counsellors in order to understand what psychosocial support was offered. MEHE had introduced psychosocial support in response to the needs of Syrian children and the receipt of donor funding for it in 2015. This new service was introduced only for the afternoon shift as part of the overall response plans LCRP and RACE I and II. In 2015, educational counsellors were appointed to provide psychosocial support to Syrian students in the afternoon shift only. Interestingly, students in the morning shift, which included both Lebanese and Syrian students, were not offered this support. This could be because MEHE policy was to enrol refugee children who fled the war in Syria in the afternoon shift while Syrian children living in Lebanon prior to the crisis were enrolled in the morning shift. However, we observed a few Syrian students in the morning shift who had fled the war. Moreover this approach assumed that Lebanese children did not need this support, although students in both shifts reported emotional difficulties. Four out of the five visited schools had educational counsellors in the second shift. Most of the interviewed counsellors recommended psychosocial support for both Syrian and Lebanese students in the morning shift, rather than exclusively for Syrian children in the afternoon shift.

The majority of counsellors had backgrounds in the social sciences, and some had experience in NGOs and international agencies, yet none had a background in psychology. Educational counsellors typically collaborated with the head teacher or the principal and spent 45 minutes every week with each class. They also worked with an average of 20 to 30 students per week and spent an average of 30 minutes with each student. In meetings, counsellors focused primarily on asking children about what bothered them or made them sad, and then offered advice. Some counsellors facilitated drawing and other activities to help students open up. One counsellor stated, "I try to gather more information about students with problems. I talk to them, comfort them, encourage them, and give them more hope." Another counsellor explained that psychosocial support was offered as a way for students "to communicate in a non-violent way, decrease bullying, communicate with one another, establish self-confidence, motivation, creativity, and self-protection, to accept others, and to accept difference. These themes were handed out to us by MEHE."

In cases of trauma or sexual abuse as well as other severe experiences, counsellors asked to see the children's parents, or these cases were referred to the Centre for Guidance and Counselling at MEHE or to supporting NGOs for more specialized help. Students with severe behavioural problems, such as bullying and restlessness, tended to be eventually expelled after meetings with their parents failed to change their problematic behaviour.

\section{Sources of Psychosocial Distress}

When examining the factors that might affect students' psychosocial condition, we identified three kinds of distress: pre-existing, ongoing, and future. Pre-existing distress is 
mainly war-related; ongoing distress is socio-economic (especially poverty), fear of movement, and education inequity; and future distress is due to uncertainty.

\section{War-Related Distress}

A few severe cases of children's war-related trauma were brought up during interviews with teacher administrators and in focus group discussions with children and educational counsellors (offered in most of the visited schools in the second shift). The counsellors argued that severe cases of psychosocial distress were due to witnessing armed conflict and violence, as well as loss of close family members. These children exhibited stuttering, crying, depression, and other behavioural issues. In some second-shift focus group discussions with Syrian children, girls often reported experiencing a major trauma or loss of a close family member. Boys, on the other hand, were reluctant to talk about the trauma they witnessed in Syria and were more concerned with the present bullying and the violence of Lebanese children on their way to and from school.

Several administrators and social counsellors related stark behavioural issues corresponding to war-related experiences. However, interviews with students and their parents, teachers, and administrators showed that the majority of children were affected by present distress and future uncertainty similar to that of their parents. The major ongoing forms of distress reflected the fear of movement and poverty, as well as uncertainties about the future due to the potential for reification. Syrian refugees had few opportunities to participate in social life on a par with local citizens.

\section{Present Socio-economic Distress}

A wealth of literature points to poverty as a central factor affecting mental health and emotional well-being. Numerous studies demonstrate higher rates of behavioural and emotional difficulties among children growing up in families and communities with higher levels of deprivation (Banerjee et al., 2016; McLoyd, 1998).

The assessment of the psychosocial distresses of children reveals that family socio-economic conditions are determining factors in their psychosocial and mental conditions. When asked to recall the last time they were happy, many Syrian children answered that their unhappiness was related to their parents' continuous anxiety and poor living conditions. In other words, the emotional stress of refugee children was associated with the experiences of their parents outside the school. Thematic categorization of Syrian children's psychosocial distress showed that out-of-school stress was far more traumatic than that experienced in school. It also showed that the relationship between Syrian and Lebanese children in Lebanese public schools reflected the wider relationship between Syrian refugees and local communities, which was characterized by segregation and neglect from authorities and translated into a struggle over inadequate resources and poor services.

In discussions with Syrian refugee students who attended the afternoon shift, none of the 10 randomly selected children were able to recall the last time they felt happy. In contrast, they freely reported trauma and anxiety. Concerns for their parents and family members were recurring sources of anxiety, followed closely by lack of financial resources. Girls, on the whole, expressed a greater sense of trauma and loss. Yet they also worried about their parents and the pressures of insecurity. One girl who asked to be interviewed alone described how concerned she was about her mother, who often cried and mourned the loss of her brother. She explained, "I try not to cause her trouble and help her at home to make her feel happy, but she is always sad." Another girl noted, "I worry about my dad, as he is trying to bring his mother who lost her arm as a result of the war to Lebanon, but he cannot," as a result of the fear of movement and lack of financial means.

Administrators and teachers had varied perceptions of Syrian parents. Some argued that children's psychosocial and learning problems were due mainly to parents' ignorance and carelessness, whereas others suggested that these problems were the result of systemic socio-economic disadvantages suffered by both parents and children. When asked about children's major needs, the majority of psychosocial counsellors held the latter view. They emphasized the need to improve the socio-economic conditions of Syrian and Lebanese parents so that they could adequately provide for their children. One counsellor stated, "Children and adults need to feel they are valued, respected, and esteemed." One Syrian parent made the dubious suggestion that "when the elders are safe, it will get better for kids." A teacher captured the essence of the unfortunate situation: "Many children in grade one come with no jackets or warm shoes. You feel helpless sometimes."

Despite the efforts of UN agencies, many Syrian refugee families still perceive education as a financial burden. Limited access to aid, proper housing, clean water, sufficient power supply, and adequate living conditions in the camps often pushes them into prioritizing work over education. The ripple effects of poverty shape the psychosocial condition of Syrian children. Many have experienced violence and neglect, including domestic violence that stems from parents' inability to cope with their disadvantaged socio-economic conditions. This was reported by Syrian as well as Lebanese families. This violence is then reflected in the schools amongst students. 
Other forms of violence or neglect are perpetrated by parents as a "necessity," in return for safety or financial independence. These forms of distress include house confinement, particularly for girls and women; child labour; early marriage; and discouragement from attending school. Many children are forced to leave school and work with their fathers or in harsh work environments, where they are exposed to exploitation and abuse. Many parents also understandably prioritize moving to places where they can find new jobs, regardless of how far they are from their children's school, discouraging them from attending school or forcing them to drop out. Most of these children end up working with their fathers or are exploited as low-cost labour in local shops and businesses.

\section{Fear of Movement}

At first glance, the Lebanese "No refugee camp" policy offers freedom of movement to Syrian refugees. However, closer inspection reveals its unseemly implications. Neighbourhoods and local communities, rather than the government, have become responsible for hosting and regulating the Syrian presence and establishing their own forms of vigilante control and security within their own territories. And government neglect of its responsibilities is not a phenomenon unique to Syrian refugees. State neglect in crises is the hallmark of how it has treated disadvantaged Lebanese and Palestinians.

The consequences of this neglect is apparent in the emotional well-being of children. Refugee children told education counsellors about their persistent fears of kidnapping, exploitation, sexual harassment, and harm to their families. These fears led parents to refrain from sending their children to schools, or left children with little choice but to drop out. Psychosocial counsellors reported that many children were subject to sexual harassment by people such as landlords or local shopkeepers. But relatively few children mentioned experiencing actual attempts of kidnapping. A field assessment by the Norwegian Refugee Council (2013) found that Syrians and other refugees in Lebanon were frequently stopped at police or vigilante checkpoints, were humiliated, are detained, and/or are threatened with deportation. Fear of abduction and abuse-experienced by both parents and children-was perpetual, regardless of whether the trip was to the workplace, the local shop, or school.

Parents perceived the restriction of their children to afternoon public school shifts as another indication of an unwelcoming and threatening environment. Their primary method of coping was self-confinement, in order to avoid the possibility of threat and humiliation, so they retreated from social life and abandoned their attempts to improve their situation.
They discouraged their children from attending school or pushed them to drop out as a result of concerns about security or inability to afford costs of transportation. Many preferred to keep their children without education, because they were unwilling to trade their children's education for their safety.

\section{Present Distress: Access to Quality and Inclusive} Education

Access to quality education has become a main source of stress. While acquisition of a foreign language (English and French) was cited as the primary barrier facing Syrian students in Lebanese schools, a number of school principals, teachers, and parents asserted that both Syrian and Lebanese students faced difficulties in other subjects as well. School staff highlighted the need to improve the curriculum and support public schools with much-needed resources and extracurricular activities as well as classes in art and physical education, or cultural events. These were also the needs most frequently reported by both Syrian and Lebanese students in the survey.

Most principals asserted the need for teacher education and qualified recruitment, and for more administrative autonomy. One teacher was frustrated by being restricted to using only curriculum materials and pedagogies: "I need more power and freedom to act and take decisions ... the resources are limited."

It would be misleading to reduce the issue of quality education to notions such as "refugee education" or to the afternoon shift. The challenges that undermine the quality of education in public schools are structural and rooted in factors that precede the outbreak of the Syrian conflict. There have been four attempts to reform education since the end of the Lebanese civil war in 1989, most of which had limited success (Shuayb, 2016).

When students were asked what would improve their psychosocial well-being, $32 \%$ said they would change cruel teachers or staff; $28 \%$ said facilities (smaller classes, better seats and desks, cleanliness, heat, libraries, clubs, cafeterias, computers, and sports facilities); $27 \%$ mentioned extracurricular activities (breaks, play, entertainment, art, and sporting activities); and $13 \%$ mentioned safety and security (protection against bullying, noise reduction, and more justice between students and staff).

The afternoon shift significantly affects the exposure of Syrian and Lebanese children to one another. Around $40 \%$ of Lebanese students claimed they had only Lebanese friends, while $60 \%$ of Syrian students claimed they had only Syrian friends. Morning shift Syrian students had Lebanese friends $(74 \%)$, compared to only $27 \%$ in the afternoon shift. 
The segregation of Syrian and Lebanese students into two separate shifts affected social cohesion and has resulted in bullying.

Some principals reported jealousy caused by inequality. Lebanese and Syrian students in the morning shift felt privileged because they received longer lunch breaks and had time for extracurricular activities. One Syrian student described himself as a Syrian, "but a morning shift student," implying that he had higher status. Lebanese students in the morning shift blamed Syrian students in the afternoon shift for damaging the classroom and were jealous of the supplemental assistance given to the refugees. One principal claimed that some Lebanese parents "told [me] to stop taking Syrian children.” In contrast, many Syrian students demanded to be transferred to the morning shift. Syrian parents claimed that the lower quality of education in the afternoon shift exhausted their children and was the primary reason that they dropped out. A teacher confirmed these power dynamics and the struggle among students over resources: "They fight a lot, especially when the Syrians get some aid [mainly stationery or cost of transport]."

\section{Future Distress: Uncertainty}

Interviews revealed that Syrian children and parents perceived their stay in Lebanon as temporary, so survival was their priority. Being labelled as refugees had made them subordinate and restricted their movement. The majority of interviewed Syrian parents and children operated in "survival mode" and were far from perceiving their presence as a new beginning. Their anxiety about the future was repeated continuously in the focus group discussions. Some parents noted that it pushed them to take the risk of going to Europe by sea and potentially drowning with their children, rather than await a hopeless future in Lebanon.

This section concludes with a reflection on sources of stress. The clinical and psychosocial schools of intervention offer few answers. Emphasis on past trauma and mere subsistence in the present does not respond to refugee aspirations to exceed or simply restore their prior social positions and to preserve their individual identities. Nor does it speak to the anxieties, uncertainties, and bleak futures faced by refugees. Many refugees expressed a desire to be reborn, wanted, and cared for, free from destitution, humiliation, and helplessness, able to pursue their hopes and aspirations.

\section{Discussion and Conclusion}

One central finding of this article is that traumas overlap and exacerbate one another. The trauma of exposure to, displacement by, and survival in an ongoing war affects refugees. But living in poverty without the prospect of a better future is similarly traumatic. These findings support earlier studies that show that economic pressure affects adolescents' mental health, both directly as a source of stress and indirectly through reduced resources that may protect against the impact of traumatic events (Khamis, 2012, 2015; Hobfoll, 1989). Most psychosocial and mental health interventions emphasize war-related trauma, or, in other words, the residual impact of past distress, while overlooking present and future distress.

The struggle over resources between adult Syrian refugees and the local Lebanese communities is reproduced in the school space between Syrian refugee children and the majority of impoverished Lebanese students. The territorial divide that parents experience through camp confinement and restrictions on mobility is imposed on students through their confinement to the afternoon shift. While the adults are divided by territory, the children are divided by shifts. Although the quantitative analysis shows no significant difference on the emotional level between Syrian and Lebanese students, the qualitative data show that Syrian students suffer from anxiety, nervousness, and misfortune associated with their parents' concerns and socio-economic condition.

Ad hoc assistance for deprived people may save the day, but it does not free them from exploitation and violence in destination countries that are often unfamiliar with and hostile to newcomers. Nor does it provide refugees with an opportunity for a new beginning. Humanitarian assistance only satisfies immediate needs. It does not provide freedom from the fear of being left behind and of becoming a "nobody," unentitled to self-determination, esteem, participation, and status. Emphasis on past trauma and present subsistence (i.e., focusing on the clinical and psychosocial approach and conditional relief provisions) does not respond to newcomers' desire to restore autonomy and social position. Nor does it offer avenues to preserve their privacy and individual identity or address their deepest anxieties and uncertainties about the future. Ad hoc interventions neglect the right to self-determination by imposing a precarious condition and promoting dependence on aid systems for subsistence. For many newcomers as well as local communities, past traumas are of far less concern than those of regenerating and transforming themselves amid a dire situation while also facing a precarious future.

To conclude, this study aimed to understand the psychosocial experiences of Lebanese and Syrian refugee children and the provisions made for them. However, it sought to do so while encompassing the socio-economic situation that engulfs all children in Lebanon. While the findings of this study cannot be generalized as a result of the limitations of the methodology and sampling, they shed light on the need 
to move away from a clinical approach to dealing with refugees' emotional well-being. Currently, refugees are plagued by extreme poverty in addition to a precarious future, which alone is a consistent source of trauma. In conclusion, structural changes that encompass the present and create opportunities and hopeful avenues for the future are key to the emotional well-being of children.

\section{References}

Abou-Saleh, M., \& Mobayad, M. (2013). Mental health in Syria. International Psychiatry, 10(3), 58-60.

Alfadhli, K., \& Drury, J. (2016). Psychosocial support among refugees of conflict in developing countries: A critical literature review. Intervention, 14(2), 128-141. https://www. interventionjournal.com/sites/default/files/Psychosocial_support_among_refugees_of_conflict_in.6.pdf

Atlas, M. (2009). Experiencing displacement: Using art therapy to address xenophobia in South Africa. Development, 52(4), 531-536.

Banerjee, R., McLaughlin, C., Jess, C., Roberts, L., \& Peereboom, C. (2016). Promoting emotional health, well-being and resilience in primary schools. The Public Policy Institute for Wales.

Berthold, S. M. (2000). War traumas and community violence: Psychological, behavioural, and academic outcomes among Khmer refugee adolescents. Journal of Multicultural Social Work, 8(1-2), 15-46. https://doi. org/10.1300/J285vo8no1_02

Betancourt, T. S., Borisova, I., Williams, T. P., Meyers-Ohki, S., Rubin-Smith, J., Annan, J., et al. (2013). Research review: Psychosocial adjustment and mental health in former child soldiers-A systematic review of the literature and recommendations for future research. Journal of Child Psychology and Psychiatry, 54(1), 17-36.

Bush, K., \& Saltarelli, D. (200o). The two faces of education in ethnic conflict: towards a peace building education for children. UNICEF Innocenti Research Centre, Florence.

Fazel, M. (2018). Psychological and psychosocial interventions for refugee children resettled in high-income countries. Epidemiology and Psychiatric Sciences, 27, 117-123. https://doi.org/10.1017/s2045796017000695

Goodman, R., Meltzer, H., \& Bailey, V. (1998). The Strengths and Difficulties Questionnaire: A pilot study on the validity of the self-report version. European Child and Adolescent Psychiatry, 7, 125-130. https://doi.org/10.1007/ so07870050057

Government of Lebanon and UNHCR. (2019). Lebanese crisis: Response plan, 2017-2020 (2019 update). https://reliefweb.int/sites/reliefweb.int/files/resources/67780.pdf

Gupte, J., \& Mehta, L. (2009). Disjunctures in labelling refugees and oustees. In R. E. Joy Moncrieffe (Ed.), The power of labelling: How people are categorized and why it matters (pp. 64-79). Earthscan.

Hassan, G., Ventevogel, P., Jefee-Bahloul, H., Barkil-Oteo, A., \& Kirmayer, L. J. (2016). Mental health and psychosocial wellbeing of Syrians affected by armed conflict. Epidemiology and Psychiatric Sciences, 25, 129-141. https://doi. org/10.1017/S2045796016000044

Hobfoll, S. E. (1989). Conservation of resources: A new attempt at conceptualizing stress. American Psychologist, 44(3), 513-524. https://doi.org/10.1037/0003-066X.44.3.513

Huyck, E. E., \& Fields, R. (1981). Impact of resettlement on refugee children. The International Migration Review, 15(1-2), 246-254. https://doi.org/10.1177\% 2Fo197918381015001-225

Institute of Medicine. (2015). Psychosocial interventions for mental and substance use disorders: A framework for establishing evidence-based standards. The National Academies Press. https://doi.org/10.17226/19013

Inter-Agency Standing Committee (IASC). (2007). IASC guidelines on mental health and psychosocial support in emergency settings. IASC.

Khamis, V. (2012). Posttraumatic stress and worry as mediators and moderators between political stressors and emotional and behavioral disorders in Palestinian children. International Journal of Psychology, 47(2), 133-141. https://doi.org/10.1080/00207594.2011.598524

Khamis, V. (2015). War, religiosity, ideology and PTSD in the Middle East. In V. R. Preedy (Ed.), Comprehensive guide to post-traumatic stress disorder. Springer International Publishing.

McLoyd, V. C. (1998). Socioeconomic disadvantage and child development. American Psychologist, 53(2), 185204. https://doi.org/10.1037/0003-066X.53.2.185

Ministry of Education and Higher Education (MEHE). (2014). Reaching all children with education: RACE I.

MEHE. (2016). Reaching all children with education: RACE II (2017-2021).

MEHE. (2019). RACE II Fact Sheet: March 2019. http://racepmulebanon.com/images/fact-sheet-march-2019.pdf

MEHE. (2020). Reaching all children with education: Lebanon (RACE II). http://racepmulebanon.com/index.php/ features-mainmenu-47/race2-article).

Norwegian Refugee Council. (2013). The consequences of limited legal status for Syrian refugees in Lebanon: NRC Lebanon Field Assessment Aarsal and Wadi Khaled.

Nosè, M., Ballette, F., Bighelli, I., Turrini, G., Purgato, M., Tol, W., Priebe, S., \& Barbui, C. (2017). Psychosocial interventions for post-traumatic stress disorder in refugees and asylum seekers resettled in high-income countries: Systematic review and meta-analysis. PLOS ONE, 12, 1-16. https://doi.org/10.1371/journal.pone.0171030 
Panter-Brick, C., Eggerman, M., Mojadidi, A., \& McDade, T. W. (2008). Social stressors, mental health, and physiological stress in an urban elite of young Afghans in Kabul. American Journal of Human Biology, 20(6): 627-641. https://doi.org/10.1002/ajhb.20797

Patel, V. (2014). Rethinking mental health care: Bridging the credibility gap. Intervention 12(Supplement 1): 15-20. https://www.interventionjournal.com/sites/default/ files/Patel\%202014\%20I\%2obridging\%2ocredibility\%20 gap.pdf

Pérez-Sales, P. (2013). Assessment of trauma experience, mental health and individual and community coping resources of refugee Syrian population displaced in north Bekaa (Lebanon). Médecins du Monde-France / Médicos del Mundo-España.

Perez-Sales, P., Médecins du Monde. (2013, January 28). Assessment of trauma experiences, mental health and individual and community coping resources of refugee Syrian population displaced in north Bekaa, Lebanon.

Shuayb, M. (2016). The role of research centres in shaping education reform in Lebanon. Al Moustakbal, N443: 84-102.

Shuayb, M., Makkouk, N., \& Tuttunji, S. (2014). Widening access to quality education for Syrian refugees: The role of private and NGO sectors in Lebanon. http://lebanesestudies.com/wp-content/uploads/2014/o9/Widening-Access-to-Quality-Education-for-Syrian-Refu-
gees-the-role-private-and-NGO-sectors-in-Lebanon-. pdf

Turrini, G., Purgato, M., Acarturk, C., Anttila, M., Au, T., Ballette, F., \& Barbui, C. (2019). Efficacy and acceptability of psychosocial interventions in asylum seekers and refugees: Systematic review and meta-analysis. Epidemiology and Psychiatric Sciences, 28(4), 376-388. https://doi. org/10.1017/S2045796019000027

United Nations. (2016). Regional refugee \& resilience plan (3RP) 2015-2016: Regional strategic overview.

United Nations and Government of Lebanon. (2015). Lebanon Crisis Response Plan 2015-2016.

United Nations High Commissioner on Refugees (UNHCR). (2015). UNHCR report 2015: Lebanon crisis response plan 2015-2016. https://www.unocha.org/sites/dms/ CAP/2015-2016_Lebanon_CRP_EN.pdf

UNHCR. (2013). Syria crisis: Education interrupted. http:// www.refworld.org/docid/52aebbco4.html

Maha Shuayb is director of the Centre for Lebanese Studies at the Lebanese American University, Beirut, and an associate lecturer at University of Cambridge, Faculty of Education. She can be reached at maha.shuayb@lebanesestudies.com

Nader Ahmad is a research assistant at the American University of Beirut.He can be reached at naa86@mail.aub.edu 